\title{
The Ability of Thai Herbal Household Plant Crude Extracts (Alpinia Galangal) in Growth Inhibition of Mold Aspergillus Flavus and Destruction of AflatoxinB1
}

\author{
By Pinyapach Dungkokkruad ${ }^{1}$, Jatupol Jutirak ${ }^{2}$, Nutsuda Wongkamsom², \\ Pattama Kongsee ${ }^{2}$, Montol Saichi ${ }^{2}$, Atchariya Meesa-ad ${ }^{2}$
}

\begin{abstract}
AflatoxinB1 (AFB1) produced from mold Aspergillus flavus (A. flavus) contaminated in foods causing in liver cancer. This study aims to inhibit the growth of A. flavus and destroy AFB1 by using the crude extracts in water of Thai herbal household plants such as ginger, galangal, garlic and elephant garlic. Quantity of Free AFB1 was analyzed by ELISA. The results indicated that crude extract of galangal could inhibits the growth of mold at $30.8 \%$, followed by elephant garlic and garlic were at 4.3 and $1.8 \%$, respectively, while ginger could not inhibit the growth of mold at all conditions. In addition, the concentration at 1:10 w/v with all $\mathrm{pH}$ range, especially at regular $\mathrm{pH}$ condition of 4.6 was the highest inhibition ability at $73.4 \%$. In addition, galangal crude extract at 1:10 $\mathrm{w} / \mathrm{v}$ showed the ability to decrease AFB1 at all $\mathrm{pH}$ conditions. However, at $\mathrm{pH} 4.6$, the toxin was destroyed within 24 and 72 hrs at 63.4 and $81.9 \%$, respectively. From the results, the crude extracts of galangal could inhibit the growth of A. flavus and destroy the mold toxin as AFB1. Therefore, the application of herbal household plant as food ingredients to prevent the poison from AFB1 is interesting.
\end{abstract}

\section{Introduction}

The Aspergillus flavus is the ubiquitous fungi in nature, which produced the secondary metabolites as aflatoxin (AF) and classified as one of the most potent carcinogens when contaminating food grains (Stoloff, 1977). They occur in numerous crops including peanuts, cereals (Tamil et al., 2002). Almost of crops has been preserved by food processing for long time causes to microorganism growth especially mold and has also economic problems. Aflatoxins have various type such as aflatoxinB1 (AFB1), aflatoxinB2 (AFB2), aflatoxinG1 (AFG1) and aflatoxinG2 (AFG2). Among these, AFB1 is the most toxic than any other analogue which are listed as group I carcinogens by the International Agency for Research on Cancer (IARC, 1993) and could lead to acute hepatic destruction, cirrhosis and some malignancies as well as immunodeficiency causing recurrent infections (Diener and Davis, 1966). Consequently, many of committees and institutes have defined standards for acceptable amounts of AF. For instance, a European committee named "Codex" has defined an acceptable amount for AFB1 is $5-10 \mathrm{ppb}$ in feedstuffs and $4 \mathrm{ppb}$ in foodstuffs (Cater, 1974). The allowed amount which has already been defined in Thailand is $20 \mathrm{ppb}$ for aflatoxin (Thai FDA, 1986).

Many studies have been performed in order to control the contamination of human and 
animal foods through physical methods such as atmospheric pressure and ambient temperature (Price et al, 1982), chemical method such as strong acid/basic, and biological methods such as lactic acid bacteria (Carolyn, 2010). There are various herbal plants extract such as galangal, clove, hot basil, garlic, lemon grass, and shallots could inhibit the growth of some strain of fungi. However, hot basil and basil could found to destroy Aflatoxin. (Soliman et al, 2002, Taechowisan et al 2012)

This study was carried out to investigate the inhibition growth of Aspergillus flavus, and the destruction of aflatoxinB1 by the extraction of Thai herbal household plants for applying as ingredients in food with safety.

\section{Material and Method}

\subsection{Herbal plants Extraction}

The herbal plants such as ginger, galangal, garlic, and elephant garlic were collected from the market at Mahasarakham municipal. The herbal plants were cleaned and then dried in hot air oven at $60^{\circ} \mathrm{C}$ for 72 hours. The dried herbal plants were ground into powder, then dissolved to solution in distilled water $(0.1 \% \mathrm{w} / \mathrm{v})$ for 24 hours and filtered by filter paper (Whatman No.1), and stored at $4 \pm 2{ }^{\circ} \mathrm{C}$ for further experiments.

\subsection{Microbial culture and growth inhibition assay}

A strain of $A$. flavus TBRC 2523 was maintained at $5^{\circ} \mathrm{C}$ on potato dextrose agar (PDA) slants.

Method I: The studied of inhibition growth of $A$. flavus with different strain of plants, were performed using poisoned food technique. PDA medium $9 \mathrm{ml}$ was prepared mixing with each $1 \mathrm{ml}$ of herbal plants crude extracts $(0.1 \% \mathrm{w} / \mathrm{v})$. A control without the extract was prepared by transferring an equivalent amount of distilled water. Agar plugs (10 $\mathrm{mm}$ diameter) taken from the growing margins of the mold colonies were aseptically placed in the center of each treatment Petri plate. The Petri plates of mold were cultured and incubated in room temperature $\left(25 \pm 30^{\circ} \mathrm{C}\right)$ for 7 days. After the incubation period, the plates were examined and the diameter of the growing colonies measured in two directions at right angles to each other. All experiments were carried out with at least three separate replicate Petri plates per treatment. The growth inhibition was calculated as follow;

$\%$ growth inhibition $=100-\left(\mathrm{r}^{2} / \mathrm{R}^{2} \times 100\right)$

$\mathrm{r}=$ Average radius of mold colony in experimental Petri plate

$\mathrm{R}=$ Average radius of mold colony in control Petri plate

Method II: The studied of inhibition growth of $A$. flavus with different concentration of galangal $(0.1,0.05,0.033$ and $0.025 \mathrm{w} / \mathrm{v})$ by poisoned food technique as manner above.

Method III: The studied of inhibition growth of $A$. flavus with different $\mathrm{pH}$ condition $(\mathrm{pH}, 6,7,8$ and 9). PDA medium $9 \mathrm{ml}$ was prepared mixing with each $1 \mathrm{ml}$ of herbal plants crude extracts $(0.1 \% \mathrm{w} / \mathrm{v})$, and mix with $1 \mathrm{ml}$ of buffer solution at $\mathrm{pH} \mathrm{5,6,7,8}$ and 9 per Petri plate. A control without the extract was prepared by transferring an equivalent amount of distilled water and buffer solution same $\mathrm{pH}$ as the same manner above. 


\subsection{The studied of AFB1 destruction ability}

The destruction ability of AFB1 were operated using standard AFB1, which was purchased from Sigma (St Louis, MO). Prepared the standard AFB1 $20 \mathrm{ppb}$ in sample dilution buffer $(7 \mathrm{ml} \mathrm{MeOH}+92 \mathrm{ml} 0.01 \mathrm{M} \mathrm{PBS}+1 \mathrm{ml}$ Dimethyl formamide). Transfer $3 \mathrm{ml}$ of galangal crude extract into $50 \mathrm{ml}$ tube, and then add $3 \mathrm{ml}$ of standard AFB1 per tube (1:1). Prepare negative control by using galangal crude extract mix with distilled water. For the positive control, using standard AFB1 mix with distilled water. All experiments were carried out with at least three separate replicate tubes per treatment. Incubate all tubes in the dark room for 24 and 72 hours. Quantity of free AFB1 were analyzed by ELISA method, data were analyzed by frequency, percentage, and standard deviation.

\subsection{Analyze of free AFB1 quantity}

Preparation of Aflatoxin Standards. The AFB1 working standards were prepared by diluting the stock solution in $80 \%$ methanol to obtain $100 \mu \mathrm{g} / \mathrm{L}$ of AFB1. From $100 \mu \mathrm{g} / \mathrm{L}$ of $\mathrm{AFB} 1$ at 33.3, 11.1, 3.7, 1.2, $0.4,0.14 \mu \mathrm{g} / \mathrm{L}$ were obtained by serial dilution in glass tubes.

ELISA Protocols (Antibody Coating Protocol). Microwells were coated with anti-AFB1 antibody at $10 \mu \mathrm{g} / \mathrm{mL}$ in carbonate buffer (0.05 M carbonate buffer, $\mathrm{pH}$ 9.6) overnight. After washing the wells with PBS containing 0.05\% (v/v) Tween 20 (PBS/T), 1\% fish gelatin hydrosate $(\mathrm{FGH})$ in PBS were incubated for $1 \mathrm{~h}$. The excess blocking solution was removed by washing with the PBS/T. All incubations were performed at room temperature.

Standard Assay. Drop $50 \mu \mathrm{l}$ of standard AFB1 into the test wells for 4-5 concentration above. $50 \mu \mathrm{l}$ galangal crude extract and $50 \mu \mathrm{l}$ HRP enzyme conjugate (diluted in 1\% BSA in PBS) were added to the antibody-coated wells, and the mixed solution was incubated for $30 \mathrm{~min}$ in the dark room. After washing with PBS/T $(0.01 \mathrm{M}$ PBS - T) three times, the substrate/chromogen solution (3,3',5,5'-tetramethylbenzidine/hydrogen peroxide in acetate buffer, $\mathrm{pH} 5.5,100 \mu \mathrm{L}$ ) was added to all the testing wells, and the plate was incubated for $10 \mathrm{~min}$. Stopping the color development with $1.25 \mathrm{M}$ sulfuric acid $(100 \mu \mathrm{L})$ to all the testing wells. The plate was read by ELISA Micro reader at wavelength $450 \mathrm{~nm}$. For control and blank wells, 16\% methanol and diluted sample extract were used in their respective standard curves. Final absorbance was calculated by subtracting the absorbance of the corresponding blank wells (background color).

\section{Results and Discussion}

\subsection{The studied of inhibition growth of $A$. flavus}

The studied of inhibition growth of $A$. flavus with different strain of herbal plants, the results show that galangal crude extract have the most effective inhibition of growth of $A$. flavus, following by elephant garlic, garlic, and ginger at 30.8, 4.3, 1.8, and $0 \%$, respectively compared with the control (Figure1). 


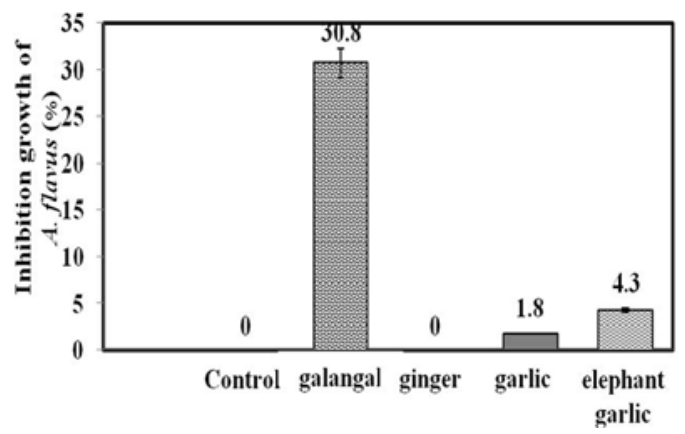

Figure1. Inbibition growth of $A$. flavus with different strain of herbal plants

From the results, the extraction of all herbal plants could inhibit the growth mold except ginger extract. This may be because of the extraction was operated using distilled water. The antifungal substance in ginger may less dissolve in water. In the other hand, others solvent such as ethanol or methanol may dissolve antifungal substance more. For the galangal, the main active substance is 1'-acetoxychavicol (Jirawan, 2006) have ability to inhibit the mold growth, whereas, garlic and elephant garlic was not. However, in garlic have much more antibacterial substance such as alliin, allicin, and dially disulfide. The mechanism of these antimicrobial expect to inhibit the enzymes cell, causes to inner protein was disturb and then the mold could not grow as usual.

The studied of inhibition growth of $A$. flavus with different concentration of galangal, the results show the concentration at $0.1 \% \mathrm{w} / \mathrm{v}$ have the highest inhibition growth of $A$. flavus at $71.8 \%$, following with $0.05,0.033$, and $0.025 \% \mathrm{w} / \mathrm{v}(55,48.3$, and $45 \%$, respectively) (Figure2).

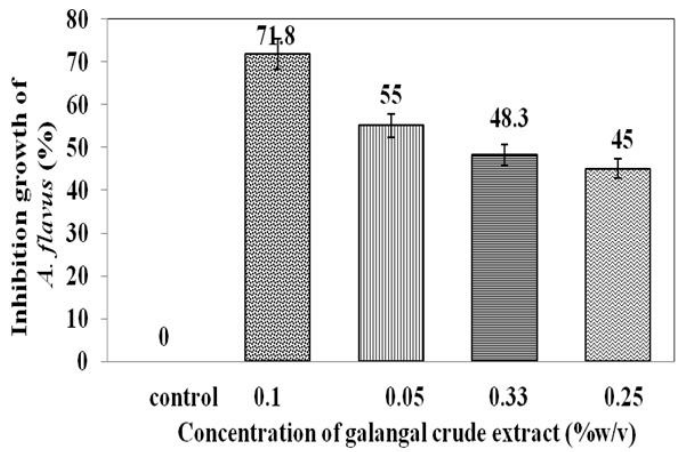

Figure2. Inbibition growth of $A$. flavus with different concentration of galangal crude extract.

From this study, inhibition of the growth of mold were observed, this result reveal that distilled water have ability to extract the active substance from galangal. The studied of inhibition growth of $A$. flavus with different $\mathrm{pH}$ condition of $0.1 \% \mathrm{w} / \mathrm{v}$ galangal, the results showed that original $\mathrm{pH}$ of crude extract at 4.6 had the most effective to inhibit the growth $A$. flavus at $74.3 \%$, following with $\mathrm{pH} 5,6,7,8(74.3,71.8,71,69.3,67.5$, and 66.8, respectively compared with control). Therefore, the increasing of $\mathrm{pH}$, the decreasing of effectiveness (Figure3). 


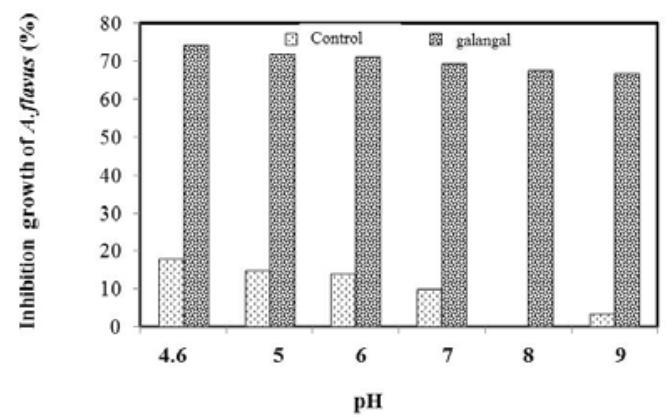

Figure3. Inbibition growth of $A$. flavus with different $p H$ of galangal crude extract.

\subsection{The studied of AFB1 destruction ability}

The studied of AFB1 destruction by galangal crude extract at various $\mathrm{pH}$ and duration times were operated. The results reveal that at original $\mathrm{pH}$ (4.6) had the most ability to destroy AFB1 for 24 and 72 hours at 63.4 and $81.9 \%$, respectively compared with positive control (Aflatoxin B1+distilled water), following with $\mathrm{pH} 6(54.5$ and $76.3 \%), \mathrm{pH} 8(54.1$ and $73.9 \%$ ), and $\mathrm{pH} 7$ (50.7 and 66\%), respectively. The higher $\mathrm{pH}$ and duration time, the less effectiveness (Figure4). Quantity of free AFB1 after destroy with galangal extract at $\mathrm{pH} 4.6$ remain at 3.3 and $2.79 \mathrm{ppb}$, respectively.
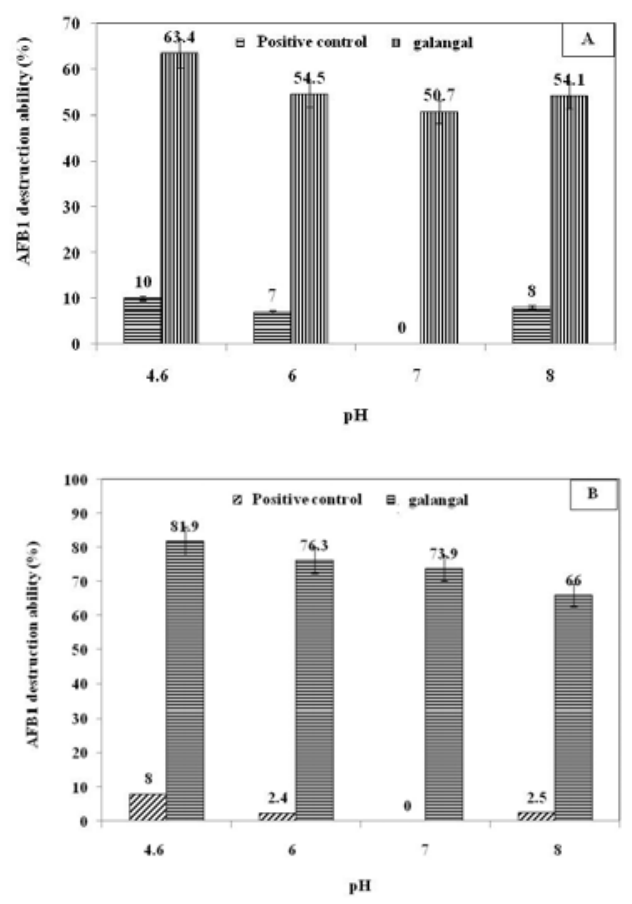

Figure4. AFB1 destruction ability (\%) with different $p H$ of galangal crude extract for 24 hours (A) and 72 hours (B). 
The present study showed that the galangal crude extract had significant inhibitory effect on growth of A.flavus and destroys AFB1 with the most effective at $1 \% \mathrm{w} / \mathrm{v}$ concentration, $\mathrm{pH}$ condition at 4.6 and duration time at 72 hours. However, the effectiveness showed very low ability in pure distilled water at pH4.6 compared with the galangal extract in water at the same $\mathrm{pH}$. Therefore, this evident could confirm that the ability of growth inhibition and AFB1 destruction absolutely causes from the antifungal substance such as 1'-acetoxychavicol in galangal. This may explain as 1'-acetoxychavicol combine with acid condition have the synergistic effect to changing the fungus cell wall. In addition, the high acid condition of cytoplasm causes to inhibit amino acid uptake into cell, then the fungus could not grow. The longtime period had the higher destruction of AFB1 due to the relation of AFB1, hydroxyl group in AFB1 have the hydrogen bound with tricarboxylic acid (Hagler, 1982).

\section{Conclusion}

The extract of galangal in water has the ability to inhibit the growth of mold as Aspergillus flavus and can be decrease the toxin of AFB1. Therefore, the using of herbal household plants as food additive or food ingredients is interesting.

\section{Acknowledgement}

This research is supported by grant from Mahasarakham University, Thailand.

\section{Reference}

Carolyn, H., Charlotte, B., Jorma, A. (2010). Factors affecting the sequestration of aflatoxin by Lactobacillus rhamnosus strain GG. Chemico-Biological Interactions; (128): 39-49.

Castells, M., Marin, V. Sanchis and Ramos A.J. (2006). Reduction of aflatoxins by extrusion - cooking of Rice Meal. J. foof sci. 71. 369- 376.

Cater, C.M., Choon, R.K., Hagenmaier, R.D., Mattil, K.F.(1974). Aqueous extraction an alternative oilseed milling process. I Am Oil Chem Soc, 51: 137-141.

Diener, U.L., Davis, N.D. (1966). Aflatoxin production by isolates of Aspergillus flavus. Phytopathol, 56: 139093.

Dilip, K. Arora,m L.A., and Mukerji, K.G.(1991). Handbook of Applied Mycology. CRC Press: 213-218.

Jirawan, O.A., Tomoko, Z., Piyawan, G., and Griangsak, E.(2006). Antimicrobial properties and action of galangal (Alpinia galangal Linn.) on Staphylococcus aureus. LWT - Food Science and Technology, 39(10):1214-1220.

Hagler, W.M., Hutchins, J.E., Hamilton, P.B.(1982). Destruction of aflatoxin in corn with sodium bisulfate. $J$ Food Prot, 45: 1287-91.

IARC. (1993). LARC Monographs on the evaluation of carcinogenic risks to bumans. Vol.56. Some naturally occurring substances: food items and constituents heterocyclic aromatic amines and mycotoxins.p.245-521.

Price, R. L., Lough, O. G., Brown, W. H.(1982). Ammoniation of Whole Cottonseed at Atmospheric Pressure and Ambient Temperature to Reduce Aflatoxin M1 in Milk. J Food Prot, 4: 292-383, 341344(4)

Tam, J., Mankotia, M., Mably, M., Pantazopoulos, P., Neil, R. J., Calway, P., and Scott, P. M. (2006). Survey of breakfast and infant cereals for aflatoxins B1, B2, G1 and G2. Food Additives and Contaminants, 23(7): 693-699 
Taechowisan, T., Chanaphat, S., Ruensamran, W., Phutdhawong, W.S.(2012). Antifungal activity of 3methylcarbazoles from Streptomyces sp. LJK109; an endophyte in Alpinia galangal.J Appl Pharm Sc: 124-128.

Soliman, K.M., Badeaa,R.I.(2002). Effect of oil extracted from some medicinal plants on different mycotoxigenic fungi. Food and Chemical Toxicology. 40(11): 1669-1675.

Stoloff, L.(1977). Aflatoxins; an overview. http://agris.fao.org/aos/records/US201301289265. 